IUPAC and the InChl Trust recommend the use of the standard InChl, an interoperable standard, as it enables linking between journals, databases, and other sources of chemical information. This interlinking is one of the major advantages of the InChl standard.

Originally developed by IUPAC, InChls are unique to the compound they describe and can encode absolute stereochemistry. The InChl was developed as a new, nonproprietary, international standard to represent chemical structures. The software is open source, with ongoing development done by the community.

Formed in 2009, The InChl Trust is a not-for-profit organization, established to expand and develop the InChl chemical structure representation algorithm. InChl Trust Members and Associates help support, shape, and direct the Trust's ongoing development: ACD/Labs, ChemAxon, Elsevier, FIZ CHEMIE, Informa/ Taylor \& Francis, IUPAC, Microsoft, Nature Publishing Group, OpenEye, The Royal Society of Chemistry, Symyx Technologies, Thomson Reuters, and Wiley.

For further information, contact Project Director Stephen Heller <Steve@InChlTrust.org>.

www.iupac.org/inchi

www.inchi-trust.org

\section{Noureddine Yassaa Awarded the 2010 CHEMRAWN VII Prize}

\section{he 2010 CHEMRAWN VII Prize for Atmospheric and Green Chemistry has been awarded to Noureddine Yassaa of the Faculty of Chemistry, University of Sciences and Technology Houari Boumediène, Algiers, Algeria.}

Yassaa received the award in recognition of his outstanding research on the occurrence and the chemistry of gas- and particulate-phase organic compounds present in the atmosphere, employing both laboratory and field measurement techniques. These compounds include species with carcinogenic and mutagenic properties and/or acute toxicity, as well as nontoxic species that may contribute to the greenhouse effect, stratospheric ozone depletion, or ozone and hydroxyl radical generation in the troposphere. He has published more than 30 scientific articles in peer-reviewed journals on such subjects as gas chro- matography, mass spectrometry, emission and flux measurements of volatile organic compounds, and the sampling and analysis of pollutants in air and airborne particles. He has recorded measurements of hundreds of organic species including organonitriles, carbonyls, organohalides, terpenes, organosulfur compounds, and aromatic species across the globe.

This inaugural CHEMRAWN VII Prize comprises a plaque and a cash award of USD 5000. The plaque

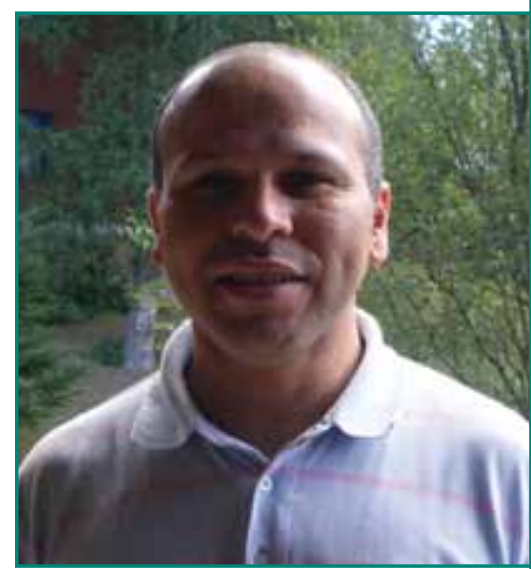

CHEMRAWN Prizewinner Noureddine Yassaa. is signed by IUPAC

President Nicole Moreau, Gerrit-Jan Koomen, chair of the Prize Selection Committee and president of the Organic and Biomolecular Chemistry Division, and IUPAC Secretary General David StC. Black.

This award was first conceived through the cooperative efforts of the CHEMRAWN VII Future Actions Committee and the Organic and Biomolecular Chemistry Division of IUPAC to recognize a young scientist from a developing country whose research contributes to the field of green chemistry, while emphasizing atmospheric chemistry.

Noureddine Yassaa was born and raised in Algiers, Algeria. He completed his studies in chemistry at the University of Sciences and Technology Houari Boumediène (USTHB) in Algiers, where he received the High Studies Diploma in Chemistry (Baccalaureate + 4) in 1995 after graduating first in his class. Thereafter, he obtained a Master's Degree in Applied Organic Chemistry at USTHB in 1997 and a Doctorate in Applied Organic Chemistry in 2001. He is currently a professor in the Faculty of Chemistry at USTHB and is also the Group Leader of the Analysis of Organic Pollutants in the Environment Research Group in the Laboratory for Functional Organic Analysis. In 2003, Yassaa was named the Best Young Researcher in Algeria, an achievement for which he received the Emeritus Medal from the National Conference of Universities. He also was awarded a special medal in 2007 from the Algerian Ministry of Environment for his work in environmental chemistry. 